\section{Pintores ilustradores. Un punto de mira}

Painters Illustrators. A Spotlight

Raquel Aguilar Alonso

Interpretar el mundo de la ilustración, en la actualidad, puede convertirse en una tarea ardua y difícil cuando buscamos una tendencia común que lo caracterice. Advertimos que no toda tendencia comun que lo caracterice. Advertimos que no toda opción es válida y que, en consecuencia, la cuestión es distinguir las ilustraciones ejemplares de nuestra época. La reflexión sobre la noción de estilo y vanguardia nos dará algunas de las pistas para discernir entre obras modernas y productos de mercado. Por último, el estudio de algunos pintores ilustradores nos ayudará a reconocer las cualidades artísticas y condiciones que convergen en una ilustración que podamos identificar como actual.

Understanding illustration today can become an arduous task when looking for a common defining characteristic. We note that Palabras clave: ilustración pintura, estilo, vanguardia, modernidad Key words: illustration, painting, style, art moder nity. not all options are valid, so we need to differentiate the representative illustrations of our time. To reflect on style and avant-garde concepts will provide us some hints to discern between modern artwork and market products. Finally, studying some illustrators painters will help us to recognize the artistic traits and conditions that come together in a contemporary illustration.
Cuando pensamos en el mundo de la llustración, en la actualidad, una gran cantidad de imágenes acompañadas de preguntas se suceden unas tras otras. Nuestro presente está plagado de imágenes y nunca tanto como ahora el lenguaje de lo visual ha inundado de tal modo nuestras vidas.

Desde que hace unos años se instaurara el sistema operativo Windows en nuestros ordenadores hasta los móviles y tabletas táctiles que hoy en día manejamos, muchas cosas han cambiado. Empecemos pensando en internet, en los navegadores y buscadores, sobre todo, de imágenes, y cómo en un solo clic un concepto puede darnos millones de entradas. En las redes sociales, sea Facebook o Twitter, entre otras muchas, en las que compartimos miles de mensajes en forma de imágenes y fotografías.

También está el ingente y variopinto mundo de los blogs. Y como no, WhatspApp, que definitivamente ha sustituido el lenguaje oral y escrito por el de los símbolos. Es decir, por imágenes con mensajes que con absoluta inmediatez asaltan nuestros móviles. Un ejemplo es el fenómeno de los emoticonos, que no solo transmiten mensajes sino sensaciones y emociones.

La lista es interminable. Miles de aplicaciones y de páginas web con varias características en común. Lo visual es el vehículo de comunicación más directo, la capacidad para reproducir imágenes roza la infinitud y no existe ninguna condición para el uso de las mismas. Sumidos en la era tecnológica, vivimos en un maremágnum de imágenes, la oferta es más amplia que nunca y el acceso a ella, muy fácil.

Ahora bien, la cuestión de cómo impacta esto en nosotros, cómo interpretamos toda esta información o cómo la seleccionamos, suscita varias preguntas: No sabemos si asistimos a un crecimiento de nuestra cultura visual o, por el contrario, a un deterioro de nuestra mirada.

En este sentido, pensemos, por ejemplo, en aquellos amantes de la fotografía, buenos capturadores del instante y cuidadosos de los encuadres que han visto decaer en picado la calidad de sus fotografías tras la implantación de cámaras en sus teléfonos móviles. O en los niños que prácticamente no saben pasar las páginas de un cuento, llegando a deslizar el índice por alguno de sus extremos del mismo modo que harían en cualquier dispositivo con pantalla táctil ante la frustración de que ahí nada se mueve, y de que tendrán que pasar página, en el sentido literal de la palabra, si desean obtener un nuevo estímulo.

En este contexto, las ilustraciones pueden confundirse con todo tipo de imágenes, lo que nos lleva a preguntarnos, qué lugar ocupan hoy en día las ilustraciones entre otros fenómenos de carácter visual que coexisten junto a ellas y cuáles son las manifestaciones que convenimos en llamar así. También, qué tendencia es la que podría describir el quehacer de los ilustradores actuales.

A lo largo de la bibliografía especializada encontramos algunas definiciones sobre el concepto de llustración como, por ejemplo, la que propone Julius Wiedemann ${ }^{1}$, en un catálogo de ilustradores actuales de reciente publicación donde destaca la diferencia entre arte e ilustración en relación a su capacidad de ofrecer un mensaje Según el autor la ilustración sería aquella que transmite un mensaje mientras que el arte sería el mensaje
VEN HELLERY JUL cargo de STEMANN, Köln, Taschen, 2013. P.7. 
mismo. Cuestión que nos introduce a algunas de las claves interpretativas del concepto pero que al mismo tiempo simplifica en exceso el tema, sobre todo, porque obvia el sentido artístico que las ilustraciones pueden tener.

Desde nuestro punto de vista, entendemos que las ilustraciones se caracterizan por contar una historia o transmitir un mensaje, sea a través de una imagen o una sucesión de varias, y por su forma, es decir, la composición, el color, el dibujo, las manchas, las texturas o la técnica que poseen. También, la relación que mantienen o integran con otras manifestaciones visuales, sean artísticas o no, como la fotografía, la animación, los videojuegos y la pintura.

Características que pueden ayudarnos a pensar en algunos ilustradores actuales, por ejemplo, en Rébecca Dautremer, ilustradora francesa muy afamada en la actualidad y con gran capacidad narrativa. Cada una de sus ilustraciones nos cuenta una historia, representan lo que ocurre en el cuento y acompañan con detalle los textos. Su técnica utiliza el claroscuro y el color, en consecuencia, sus ilustraciones poseen volumen y espacio. Nos introduce en un mundo particular, original, se trate del cuento de Pulgarcito o de Alicia en el país de las maravillas. O lo que es lo mismo, sus ilustraciones al mismo tiempo que narran, poseen una entidad formal propia que nos permite reconocer su autoría. Algo que tiene mucho que ver con las categorías formales que contienen.

El Roto, es un claro ejemplo de ilustrador de viñetas con un lenguaje formal original que le permite comunicar un mensaje de manera intensa, explícita y directa. De hecho, muchas veces, basta una de sus imágenes para transmitir una idea compleja sin necesidad de recurrir a ningún pie de foto. Sus líneas y manchas de tinta negra describen fuertes contrastes con el blanco del papel, con pocas transiciones, a veces, con contrapuntos de color. La capacidad para sintetizar la figuración obviando todo detalle que desvíe la atención del mensaje principal que transmite le confiere una gran singularidad. El mensaje se diluye en la forma, lo que lo convierte en un gran viñetista de nuestro tiempo.

Sin embargo, Michael Kutsche, muy conocido por sus trabajos relacionados con la industria del cine, como los realizados junto al director Tim Barton, es un caso bien distinto, no tanto por los medios en los que se expresa, sino por la manera en la que transmite los mensajes. Para empezar, es un creador de personajes más que de ideas y sus creaciones exigen una narración. Su forma, próxima a la fotografía o a la pintura hiperrealista es, ante todo, descriptiva. Un caso que podemos compara con el de Owen Smith, quien también ilustra utilizando un lenguaje que toma las características más superficiales de algunos movimientos de la historia de la pintura. Tal y como el mismo reconoce: "Mis ilustraciones reflejan mi interés por la pintura figurativa de 1900 a 1950. Tiendo a exagerar las proporciones y enfatizar el volumen y el movimiento."

En este sentido, nuestra cultura visual aboca de un modo u otro en el mundo de las ilustraciones. Éstas beben de la pintura, de la fotografía, del cine... Hacen uso de su lenguaje e imitan sus rasgos. Tal y como escribe Zina Saunders ${ }^{3}$ en la introducción del volumen de Claire Dalquié sobre la

ilustración actual: "Es más que evidente que estamos aprendiendo a hablar en otras lenguas y el pastiche de las traducciones está enriqueciendo y animando las conversaciones." También, afirma que "Este creciente flujo de intercambio de imágenes emocionantes, estrafalarias y muy personales busca su sitio en cualquier zona comercial y cultural del mundo"

Da la impresión de que todo cabe. Algo que nosotros no estamos dispuestos a reconocer.

Para empezar, porque los estilos abarcan periodos temporales más amplios. Pensemos, por ejemplo, en el ciclo del Renacimiento y el

Barroco, por citar una dualidad de estilos ejemplar.

Especular en la posibilidad de que, en la actualidad, estuviéramos frente al nacimiento de un nuevo estilo, cuando ni siquiera podemos reconocer rasgos coincidentes que persistan en el tiempo, resulta inverosímil, sobre todo, por la indeterminación del terreno en el que nos situamos y la carencia de perspectiva histórica que poseemos.

Además, no podemos olvidar que los estilos son expresión de una época, que cada tiempo trae un arte distinto y que la capacidad de ver es propia de un momento histórico determinado, o en palabras de Wöfflin, se debe a los diferentes "estratos ópticos" 4 de la historia artística, con su propia evolución a través del tiempo. Con lo que un retorno a estilos pasados supuestamente diversos parte de planteamientos falaces y, en el caso de producirse, solo podría hacerlo de forma trivial.

Ahora bien, con esto no obviamos la naturaleza cíclica de los estilos y sus periodos, es decir, la capacidad de cada época para asimilar e integrar soluciones anteriores, como explica Worringer: "La historia evolutiva del arte es redonda como el universo y no existe polo que no tenga su antipolo," ${ }^{5}$ sino que la distinguimos de lo que supondría reproducir solo en una obra la mera apariencia de estilos del pasado.

De este modo, ya no se trataría tanto de reconocer una posible tendencia en la actualidad, cómo en preguntarse qué manifestaciones son ejemplares de nuestra época y cuales adoptan solo los rasgos superficiales de otras. O lo que es los mismo, distinguir entre las obras que siguen el curso de la tradición, en el sentido de que son capaces de integrarla aportando soluciones nuevas en su tiempo, y las que adoptan una especie de receta, toman rasgos de aquí y allá, y crean un producto apto para el consumo.

Greenberg ${ }^{6}$, en 1939, señalaba como la revolución industrial y la

2100 Illustrators, op.cit. IIustración, hoy Nuevas tender en ilustración de vanguardia, Barce lona, Index Book, S. L, 2010. 4 WÖLFFLIN, HEINRICH, Conceptos fundamentales de la Historia del Arte, Madrid, Espasa Calpe, 2002 P. 28. 5 WORRINGER, WILHELM Abstracción y naturaleza, México, Fondo de Cultura Económica, 2008 P. 211 6 GREENBERG, CLEMENT, La pintura moderna y otros ensayos, PP. 30-34. subsiguiente alfabetización universal había dado lugar a la creación de un nuevo producto destinado a las masas ajenas a la cultura genuina, el Kitsch, en oposición a la vanguardia, portadora de los valores culturales. Como el mismo autor explicaba, el Kitsch utiliza como materia simulacros degradados y academicistas de cultura genuina, es decir, toma prestados de la tradición cultural procedimientos, trucos, estratagemas, rutinas y temas. Hoy día, tras el crecimiento exponencial que se ha producido en el ámbito del consumo, podemos intuir la dimensión que ha adquirido el atributo. Y no solo eso, sino que la capacidad de reproducción técnica que caracteriza la industrialización, comparada con el inmenso y creciente mundo de las nuevas tecnologías actuales, 
magnifican el concepto. A este respecto, resulta claro traer a colación a Walter Benjamin7 ${ }^{7}$, quien señalaba en el mismo año, cómo la técnica reproductiva desvinculaba las obras de la tradición y podía actualizarlas al llegar al receptor en cualquier contexto donde se hallase.

Por lo demás, puede resultar esclarecedor señalar que el Kitsch fomenta un consumo de fácil digestión apto para todos ya que su interpretación no requiere esfuerzo. Se basa en fórmulas aprendidas a lo largo de la historia, es decir, en ciertas maneras academicistas. En la actualidad, el poderoso impacto del mundo de lo virtual unido a la búsqueda cada vez mayor de la impresión de realidad, nos lega imágenes en las que la lectura estética es casi inexistente. Los criterios para interpretar las imágenes son otros, como la calidad del detalle, la impresión de realidad o el poder del efecto. De hecho, no es casual el desplazamiento que han sufrido las películas de dibujos animados por las de animación en las grandes factorías de la industria cinematográfica o la apuesta de los videojuegos actuales más aclamados, como Assasins Creed o Call of Duty, entre otros, por gráficos cada vez más próximos a la realidad virtual, muy valorados por el sector, como lo demuestran las publicaciones que recopilan los bocetos de los departamentos artísticos de sus respectivas industrias ${ }^{8}$.

De esta manera, el concepto de Kitsch, parece identificarse con muchas de las manifestaciones que ahora podríamos denominar postmodernas. Lo cual resulta coherente cuando pensamos en el carácter antitético que posee respecto a la vanguardia. Es decir, si el concepto de Kitsch se definió en origen por oposición a la vanguardia, con el tiempo, ambas ideas evolucionaron en sentidos distintos. La vanguardia cristalizó en una concepción nueva de entender el arte, la modernidad, cuyos fundamentos venían fragúandose desde el siglo anterior, mientras el Kitsch siempre se mantuvo al margen de dichos movimientos siendo dependiente de la ideología dominante.

La vanguardia y la modernidad enraízan con la tradición, bien sea a partir de una concepción rupturista, en la primera, o integradora en la segunda. Ambas poseen su origen en la cultura genuina, lo que les permite avanzar y profundizar en un sentido histórico. La vanguardia, por su carácter doctrinal se basa en juicios, mientras la modernidad, una vez asimilados estos principios y ajena a las convenciones queda adscrita al ámbito de la subjetividad, lo que, claro está, no la exime de poseer un carácter universal. En el gráfico (Fig. 1) ordenamos las anteiores relaciones unificando bajo la idea de "materiales,"9 en el sentido de Adorno, todos aquellos factores que emanan de una concepción histórica de la cultura. Del mismo modo, que el tránsito de éstos a la obra, lo denominamos mímesis, con un significado distinto del que solo lo identifica con la interpretación imitativa de la naturaleza. En este contexto, el Kitsch, tiene lugar a partir de la presión que ejercen los órganos de poder sobre la cultura genuina y entra en sintonía con los predicados de la ideología y el mercado.

En consecuencia, podemos interpretar que las ilustraciones que incorporen los valores de la modernidad están en condiciones de caracte-
Fig. 1. Modernidad, Vanguardia $y$ Kitsch. Raquel Aguilar, 2015

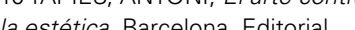
Planeta-De Agostini, S. A, 1080 PP.

11 Tamayo ilustrador, a cargo de la Raquel Tibal, Juan Carlos Pereda y Nuria Rico). México, Biblioteca de lustradores

2 Tamayo ilustrador, op. cit. P. 17

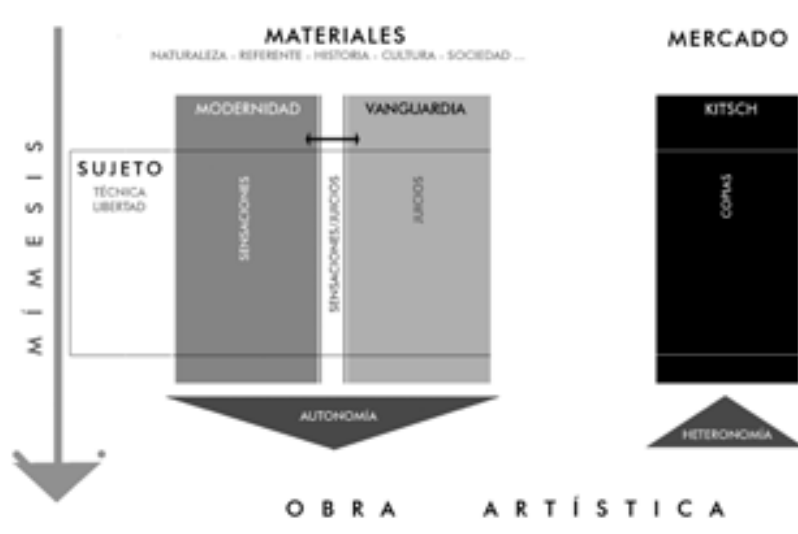

rizar nuestro tiempo, aún en este momento no definan una tendencia en común. Como Tàpies explica: "El creador -que sin saberlo ni pretenderlo se halla en los orígenes de tantas modas- huye por instinto de ellas, de su gregarismo. Es más, como dijo Herbert Read, las artes auténticas se ven comprometidas en un combate heroico contra la mediocridad y los valores de las masas -los impuestos artificialmente, claro está-, que son en realidad todo lo que está de moda o que quiere ponerse de moda."10 En efecto, no se trata de distinguir un estilo, ni tampoco la ejemplaridad de ciertas ilustraciones, sino de discriminar entre obras y productos de mercado. Siendo la primera la portadora de los valores de la cultura y la segunda, fruto de la sociedad de consumo (Fig. 2).

Desde esta perspectiva, la obra de ciertos pintores, figuras reconocidas de la modernidad, que también desarrollaron ampliamente el campo de la ilustración puede ofrecernos algunas claves para profundizar en el carácter las ilustraciones actuales por los lazos que tienden entre ambas disciplinas y su adscripción a un momento histórico concreto.

Como podemos leer en una monografía dedicada a las ilustraciones de Rufino Tamayo, pintor mejicano del siglo XX, sus ilustraciones casi siempre tuvieron carácter de pequeñas obras de caballete a pesa de que fueron creadas para embellecer, interpretar $y$, en muchas ocasiones, para enriquecer el sentido de obras escritas ${ }^{11}$. Punto de vista que nos remite al carácter propio de las ilustraciones y que nos permite situar la cualidad descriptiva de sus obras al inicio de la creación artística y no como finalidad. Es decir, la voluntad narrativa parece ser el pretexto que permite iniciar un proceso creativo, cuyo final culmina en la obra y no en el mensaje. En el mismo texto, Juan Carlos Pereda, añade: "Con sus ilustraciones Tamayo no sólo enriquece relatos o poemas, sino que partiendo de los mismos genera una nueva visión que dialoga con el texto. Más allá de una competencia entre imagen y palabra, sus dibujos, pinturas y grabados agregan otra dimensión. Estas ilustraciones no son crónica ni narración, sino jeroglíficos que significan, concentran y profundizan la esencia de los textos." 12

De la misma manera, Antonio Saura (1930-1998), uno de los pintores más relevantes de la modernidad en España que pronto asumió 

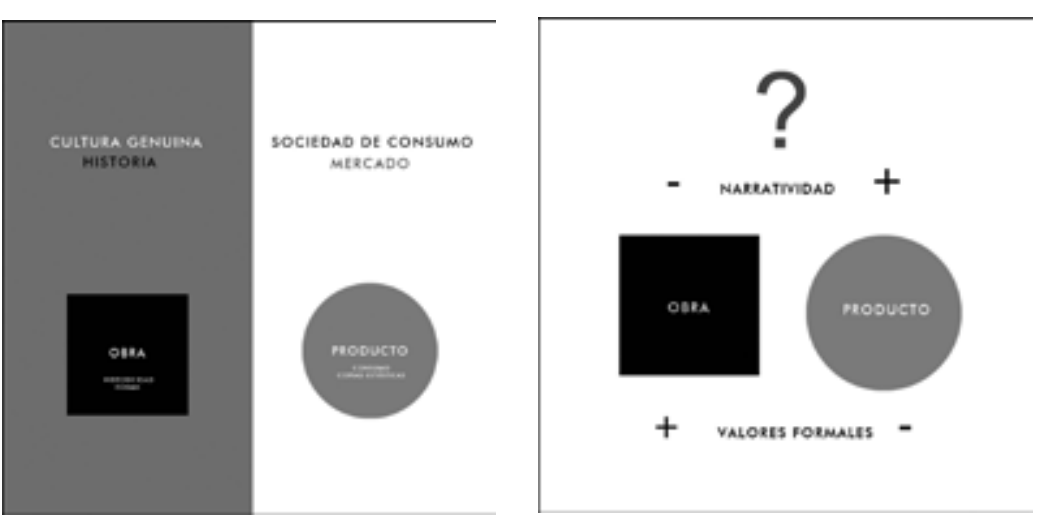

Fig. 2. Obra y producto. Raque Aguilar, 2015

Fig. 3. Valores formales y narración Raquel Aguilar, 2015. 13 El libro ruso de vanguardia 1910 1934, catálogo de la exposición Art y Madrid, Museo Nacional Centro de Arte Reina Sofia, 12 de febre ro al 5 de mayo de 2003) al cuidado de MARGIT ROWEL, DEBORAH WYE (otros textos de Jared Ash Nina Gurianova, Gerald Janecek). New York, Madrid, 2003 14 Tamayo ilustrador, op.cit. P. 12. 15 GREENBERG, CLEMENT, op cit. P. 26 los principios del informalismo europeo y el expresionismo abstracto, dedicó gran parte de su tiempo a la obra gráfica y a la ilustración. Cuando observamos sus ilustraciones, advertimos, ante todo, el vínculo que mantienen con su pintura. También, que la autonomía que adquieren sus recursos plásticos no niega su capacidad narrativa. Ilustre la obra de Miguel de Cervantes o la de Georges Orwell, la calidad y consistencia de sus creaciones es equiparable a la de sus pinturas.

Si retrocedemos un poco en el tiempo, y nos situamos en los inicios del siglo XX es necesario tener en cuenta, o al menos citar, un hecho tan destacado como especial, el del libro ruso de vanguardia ${ }^{13}$, creado por pintores y poetas futuristas. Significa un contrapunto necesario a lo que venimos tratando hasta ahora por su función doctrinaria, su base científica y teórica. En él los principios formales del constructivismo son el tema mismo de las ilustraciones y al mismo tiempo, el origen que motiva la creación de dichas publicaciones.

Una mirada distinta precisan las creaciones anteriores a las vanguardias, en las que no se han definido los predicados de la modernidad. Si volvemos la vista al siglo XIX, reparamos, en Touluse-Lautrec (1864-1901) y Honoré Daumier (1808-1879). El primero, ligado al impresionismo, se desenvuelve a nivel gráfico en el mundo de la cartelería. Las pinceladas de sus cuadros dan paso a las tintas planas y los textos componen la imagen junto a las manchas de color. La función publicitaria y descriptiva de los contenidos junto a la pérdida de la técnica que caracteriza su pintura y la identifica con un momento histórico particular convierte estas obras en una especie de subproductos de su obra pictórica. A diferencia, Honoré Daumier, parece mantener una relación inversa entre su obra gráfica y la pintura. Sus ilustraciones o viñetas, ricas en el uso de la línea propia de la técnica de la litografía son muy descriptivas y ricas en detalle. Lo que de algún modo, trasciende a su pintura, en la que reconocemos una tendencia muy marcada hacia la caracterización de personajes y transmisión de ideas.

De este modo, podemos pensar en dos ejes distintos sobre los que vertebrar las cualidades de las ilustraciones junto a su adscripción al momento histórico actual. Uno, su carácter propio, es decir, la singularidad con la que integran la narración y la forma respecto a otras manifestaciones visuales, y, dos, su capacidad para incorporar la tradición y aportar soluciones nuevas en un tiempo particular.
Raquel Aguilar Alonso

Doctora en Bellas Artes, 2014 CURRICULUM: Raquel Aguilar Valencia, 1980), es doctora en Bellas Artes (UPV 2014). Centra sus investigaciones en el ámbito de la pintura. Realiza exposiciones, se interesa por el mundo del diseño, maqueta libros y carteles. Da conferencias, escribe articulos e imparte talleres de plásti ca. En la actualidad, desarrolla nuevos res de la modernidad.

\section{Bibliografía}

ADORNO, THEODORW., Teorí estética, Barcelona, Edicion Orbis, 1983

grafí, VIN, WALTER, Sobre la fotograftia, Valencia, PRE-TEXTOS, 2007. Barcelona. Ediciones Peninsula 1987. Prólogo de Helio Piñón "Perfies encontrados."

CLAIRE DALQUIE, CLAIRE, ILUStración, hoy. Nuevas tendencias en ilustración de vanguardia, Barcelona, Index Book, S. L, 2010 GREENBERG, CLEMENT, La pintur moderna y otros ensayos, TȦPIES, ANTONI, El arte contra la estética, Barcelona, Editorial Plane estetica, Barcelona, Editorial
ta-De Agostini, S. A., 1986. WORRINGER, WILHELM, Abstracción y naturaleza, México, Fondo de Cultura Económica, 2008 WOLFFLIN, HEINRICH, Conceptos fundamentales de la Historia del Arte, Madrid, Espasa Calpe, 2002. catálogos

(934, cóso de vanguardia 1910 New York The Museum of Mo Art y Madrid, Museo Nacional Centro de Arte Reina Sofía, 12 febrero al 5 de mayo de 2003) al cuidado de Margit Rowel, Debora Wye (otros textos de Jared Ash, Nina Gurianova, Gerald Janecek). New York, Madrid, 2003 - Tamayo ilustrador, a cargo de la Fundación Olga y Rufino (textos de: Raquel México, Biblioteca de llustradores Mexicanos (BIM), RM, 2002. - 100 Illustrators, a cargo de Steven Heller y Julius Wiedemann, Köln, Taschen, 2013.
Por un lado, cabe matizar la relación entre la forma y la narración, ya que bajo nuestra perspectiva, ambas ideas no son equiparables al no poseer el mismo peso específico: mientras la consistencia formal de una obra es determinante, la narratividad, no lo es. (Fig. 3). Tal y como explicaba el mismo Tamayo "El tratamiento no descriptivo de un tema ofrece no solo mayores posibilidades de desarrollo plástico, sino también mayor posibilidad de expresión. No es cierto que los símbolos del arte no descriptivo no se entiendan; lo que ocurre es que se necesita acostumbrar a los ojos a ver esos símbolos." 14

En este sentido, si la pintura de vanguardia convirtió el proceso de pintar en el tema de sus obras, las ilustraciones pudieron realizar una operación semejante integrando en su forma los rasgos descriptivos del tema. Si tal y como señalaba Greenberg, en la pintura y la literatura, se trataba de imitar los procesos mismos de imitar, ${ }^{15}$ en las ilustraciones había que convertir los rasgos descriptivos del tema en el contenido de la obra a través de su traducción en enunciados formales. Es más mientras la pintura moderna tuvo el tema como pretexto y encontró en los procesos de mímesis una especie de limitación para no caer en lo arbitrario o accidental, la ilustración moderna pudo incorporar el tema como un principio sin adoptar soluciones representacionales.

Por otro lado, entendemos que la combinación de estilos es una característica inherente a la sociedad de consumo que ha venido creciendo gracias a las nuevas tecnologías y a la capacidad de reproducción masiva que se les desprende. Las ilustraciones que se mueven en este ámbito toman fórmulas aprendidas de otras disciplinas en aras de su eficacia, imitan sus efectos, los descontextualizan y se reproducen mecánicamente. De este modo, ninguna manifestación que tome estilos del pasado puede representar nuestro tiempo. El estilo es propio de cada época, no puede desligarse de su contexto, y mucho menos pretender que se reactive en otro nuevo.

Los pintores ilustradores modernos enraízan sin duda con la historia artística. Aportan su originalidad y su relación genuina con la concepción del arte: su historicidad. Lo que supone un garante de calidad para sus ilustraciones y nos permite adscribirlas a un tiempo particular.

En consecuencia, una ilustración preserva su entidad si en su concepción se encuentra interiorizada la historia artística que le precede, situándose en un presente consciente y comprometido con la cultura. Cualquier otro camino que lleve a la creación de una obra y que se fundamente en la reproducción de estilos juega en un fuera de tiempo y posee como único objetivo entregarse a la distribución comercial.

La historia de la llustración sigue el mismo curso que el de las otras artes, es decir, la mirada que nos permite interpretar una ilustración, no dista tanto de la que nos aproxima a otras obras. Los pintores que la han incorporado en su trayectoria, nos han ayudado a entenderlo.

Si el tema es solo el pretexto necesario de la obra pictórica, la disolución de la narración en la forma de una ilustración es uno de sus principios. Su autonomía formal, lejos de menoscabar su carácter narrativo, la vertebra y la dota de su propia historicidad. 